\title{
Ceria modified activated carbon: an efficient arsenic removal adsorbent for drinking water purification
}

\author{
Radha Sawana $^{1}$ - Yogesh Somasundar ${ }^{1} \cdot$ Venkatesh Shankar Iyer $^{1}$. \\ Babita Baruwati ${ }^{1}$
}

Received: 2 April 2014/ Accepted: 26 March 2015/Published online: 9 March 2016

(c) The Author(s) 2016. This article is published with open access at Springerlink.com

\begin{abstract}
Ceria $\left(\mathrm{CeO}_{2}\right)$ coated powdered activated carbon was synthesized by a single step chemical process and demonstrated to be a highly efficient adsorbent for the removal of both $\mathrm{As}(\mathrm{III})$ and $\mathrm{As}(\mathrm{V})$ from water without any pre-oxidation process. The formation of $\mathrm{CeO}_{2}$ on the surface of powdered activated carbon was confirmed by X-ray diffraction, Raman spectroscopy and X-ray photoelectron spectroscopy. The percentage of $\mathrm{Ce}$ in the adsorbent was confirmed to be $3.5 \%$ by ICP-OES. The maximum removal capacity for $\mathrm{As}(\mathrm{III})$ and $\mathrm{As}(\mathrm{V})$ was found to be 10.3 and $12.2 \mathrm{mg} / \mathrm{g}$, respectively. These values are comparable to most of the commercially available adsorbents. $80 \%$ of the removal process was completed within $15 \mathrm{~min}$ of contact time in a batch process. More than $95 \%$ removal of both As(III) and As(V) was achieved within an hour. The efficiency of removal was not affected by change in $\mathrm{pH}$ (5-9), salinity, hardness, organic (1-4 ppm of humic acid) and inorganic anions (sulphate, nitrate, chloride, bicarbonate and fluoride) excluding phosphate. Presence of 100 ppm phosphate reduced the removal significantly from 90 to $18 \%$. The equilibrium adsorption pattern of both As(III) and As(V) fitted well with the Freundlich model with $R^{2}$ values 0.99 and 0.97 , respectively. The material shows reusability greater than three times in a batch process (arsenic concentration reduced below $10 \mathrm{ppb}$ from $330 \mathrm{ppb}$ ) and a life of at least $100 \mathrm{~L}$ in a column study with $80 \mathrm{~g}$ material when tested under natural hard water (TDS 1000 ppm, pH 7.8, hardness 600 ppm as $\mathrm{CaCO}_{3}$ ) spiked with $330 \mathrm{ppb}$ of arsenic.
\end{abstract}

Babita Baruwati

Babita.Baruwati@unilever.com

1 Unilever R\&D, No. 64, Whitefield Main Road, Bangalore, India
Keywords Removal - Arsenic - Ceria - Activated carbon · Water purification

\section{Introduction}

Occurrence of dissolved arsenic species in drinking water and its health consequences has been a serious concern throughout the world. Several geographies across the world are affected by the presence of high concentration of arsenic in drinking water (Chen et al. 1994; Karim 2000; Zhang et al. 2010). Millions of people are at the risk of chronic arsenic poisoning in Bangladesh and India. It has been estimated that an approximate of 35-77 million people in Bangladesh are at the risk of drinking arsenic contaminated water (Ahmad et al. 1997; Chowdhury et al. 1999; Maji et al. 2008; Argos et al. 2010). Due to high health risks associated with the consumption of arsenic contaminated water and food products, the World Health Organization (WHO), European Union, and the US Environmental Protection Agency (US EPA) have set the arsenic standard for drinking water as $10 \mu \mathrm{g} / \mathrm{L}(10 \mathrm{ppb})$ to protect consumers from the long time chronic exposure to arsenic (Sabbatini et al. 2010).

Several methodologies for arsenic removal from drinking water have been reported. These include coagulation/filtration, ion-exchange, membrane technologies, chemical precipitation and adsorption (Bordoloi et al. 2013; Wickramasinghe et al. 2004; Nguyen et al. 2009; Mohan and Pittman 2007). Adsorption process is generally considered to be more attractive compared to other technologies due to ease of use and low cost (Mohan and Pittman 2007; Ali 2010, 2012). Many low cost adsorbents, e.g., iron and iron oxide based compounds, activated alumina, hydrotalcites, rare earth oxides, flyash (Zhang et al. 2003; Xu et al. 2013; Li et al. 2010; Ali et al. 2012, 2014), 
and bio sorbents have been used for arsenic removal. However, most of the studies have been reported on very fine sized adsorbent particles that would require further processing like granulation, etc., before they could be used either in community scale purification systems or point of use (POU) devices to reduce immediate caking and chocking of filters. Also many adsorbents require frequent consumer intervention like pre-oxidation, $\mathrm{pH}$ adjustment and regular regeneration process. Furthermore, use of very fine particles could lead to possible release of nanomaterials into the environment that is currently becoming an issue of concern (Cui et al. 2012). Hence development of adsorbents that are highly efficient, low cost, require minimal consumer intervention when used and do not pose threat to the environment is a need of time.

Cerium dioxide is a widely used chemically stable and nontoxic rare earth oxide which makes it a strong candidate for water purification. Cerium di oxide has been shown to have strong affinity towards arsenic and have removal capacity more than $100 \mathrm{mg} / \mathrm{g}$ when used as hydrous cerium oxide ( $\mathrm{Li}$ et al. 2012). But as stated above, the studies have been reported for nanosized particles that would require granulation before any practical applications. Granulation could lead to reduced removal capacity due to drastic change in available surface area.

Herein we have reported an efficient arsenic removal adsorbent that could directly be used in a loose bed or bound block for POU device or in community scale purification. The adsorbent consists of powdered activated carbon modified with in situ synthesized ceria particles. With equal efficiency of removal for both As(III) and $\operatorname{As}(\mathrm{V})$ without any pre oxidation, the material could be well competitive in terms of cost, ease of use and removal efficiency in comparison to any other commercially available adsorbents for arsenic removal.

\section{Materials and methods}

\section{Materials used}

Powdered activated carbon (PAC) was purchased from HAYCARB Sri Lanka. The source of activated carbon is coconut shell as mentioned by the supplier. Cerium Nitrate, Sodium Hydroxide and Hydrochloric acid were purchased from Merck Chemicals, India, and were of laboratory reagent grade. All the chemicals were used as received without any further purification or treatment.

\section{Characterization techniques}

X-ray diffraction (XRD) spectra of the samples were collected using Siemens D 5000 at a step rate of 0.5 degree two theta. Zeta potential of the samples were determined using ZETA POTENTIAL METER, MFGPRO-52400035. ICP-MS measurements were carried out using a Perkin Elmer Optima 2000 DV instrument. BET surface measurements were done using SMARTSORB-92 of Smart Instruments. X-ray photoelectron spectra (XPS) were recorded using Model ESCA+ by Omicron UK using a Al $\mathrm{k}$ alpha source. Raman spectra were recorded using Renishaw Invia Raman microscope powered by a laser source @ $785 \mathrm{~nm}$. ICP-MS studies were carried out with an Agilent-7700 ICP-MS instrument using EPA method 200.8. FTIR spectra were collected in a PERKIN ELMER SPECTRUM ONE instrument with diffuse reflectance sampling accessory.

\section{Experimental procedures}

\section{Synthesis of PAC- $\mathrm{CeO}_{2}$}

$100 \mathrm{~g}$ of powdered activated carbon was added to $80 \mathrm{~mL}$ of $0.071 \mathrm{M}$ Cerium Nitrate $\left(\mathrm{Ce}\left(\mathrm{NO}_{3}\right)_{3} \cdot 6 \mathrm{H}_{2} \mathrm{O}\right)$ solution and left undisturbed for $3 \mathrm{~h} .1 \mathrm{~N} \mathrm{NaOH}$ solution was then added drop wise to the above mixture with continuous mechanical stirring to obtain a $\mathrm{pH}$ value of 6.5 . The mixture was then filtered, washed and dried at $100{ }^{\circ} \mathrm{C}$ to yield the final material $\mathrm{PAC}-\mathrm{CeO}_{2}$.

\section{Adsorption isotherm}

$0.1 \mathrm{~g}$ of $\mathrm{PAC}-\mathrm{CeO}_{2}$ was added to $100 \mathrm{~mL}$ of $300 \mathrm{ppb}$ $\mathrm{As}(\mathrm{III})$ or $\mathrm{As}(\mathrm{V})$ solution and agitated for $4 \mathrm{~h}$. The solution was then allowed to equilibrate for $72 \mathrm{~h} .20 \mathrm{~mL}$ aliquots were collected after $72 \mathrm{~h}$, filtered through a $0.45 \mu \mathrm{m}$ syringe filter and used for arsenic estimation.

Equilibrium studies were carried out at different input concentrations of arsenic. Based on the equilibrium arsenic concentrations, an adsorption isotherm was plotted. Arsenic concentrations in the aliquots were estimated using ICP-OES.

\section{Kinetics studies}

$1 \mathrm{~g}$ of PAC- $-\mathrm{CeO}_{2}$ was added to $1 \mathrm{~L}$ of $300 \mathrm{ppb} \mathrm{As}(\mathrm{III})$ or As(V) solution. $20 \mathrm{~mL}$ aliquots were collected at 2, 4, 6, 8 and $10 \mathrm{~min}$. Further aliquots were collected at 15, 30, 60 and $90 \mathrm{~min}$. The aliquots were filtered through a $0.45 \mu \mathrm{m}$ syringe filter and clear filtrate was used for arsenic estimation.

\section{Effect of pH on removal capacity}

$\mathrm{pH}$ of $300 \mathrm{ppb} \mathrm{As}(\mathrm{III})$ or $\mathrm{As}(\mathrm{V})$ solution was adjusted to the required value using $0.1 \mathrm{~N} \mathrm{HCl}$ and/or $0.1 \mathrm{~N} \mathrm{NaOH}$ 
solution. $0.1 \mathrm{~g}$ of $\mathrm{PAC}-\mathrm{CeO}_{2}$ was then added to $100 \mathrm{~mL}$ of $\mathrm{As}(\mathrm{III})$ or $\mathrm{As}(\mathrm{V})$ solution, agitated for $4 \mathrm{~h}$ and then allowed to equilibrate for $72 \mathrm{~h}$. Aliquots were collected after $72 \mathrm{~h}$, filtered through a $0.45 \mu \mathrm{m}$ syringe filter and used for arsenic estimation.

\section{Effect of counter-ions and organics on removal capacity}

Effect of counter-ions was studied using $300 \mathrm{ppb}$ As(III) or As(V) solution spiked with $100 \mathrm{ppm}$ of the counter anion. The studies were carried out with single counter anion. For studies involving organics, $300 \mathrm{ppb}$ As(III) or As(V) solution was spiked with 1-4 ppm of humic acid. Equilibration and sample collection were done using identical procedure as $\mathrm{pH}$ studies.

\section{Reusability study}

$0.1 \mathrm{~g}$ of $\mathrm{PAC}-\mathrm{CeO}_{2}$ was added to $100 \mathrm{~mL}$ of $330 \mathrm{ppb}$ $\mathrm{As}(\mathrm{III})$ or As(V) solution agitated for $4 \mathrm{~h}$. The solution was then allowed to equilibrate for 72 h. $20 \mathrm{~mL}$ aliquots were collected after $72 \mathrm{~h}$, filtered through a $0.45 \mu \mathrm{m}$ syringe filter and used for arsenic estimation. The adsorbent was then filtered, washed with DI water and dried at RT before repeating the experiment.

\section{Column study}

$80 \mathrm{~g}$ of the adsorbent was filled in a column of $15 \mathrm{~cm}$ long acrylic column with a diameter $3 \mathrm{~cm}$ to get a packed bed. Both ends of the column were covered with fine metal mesh and porous Nylon membrane to prevent the material from flowing out. The test water [Natural water with, TDS 1000 ppm, pH 7.8, hardness 600 ppm as $\mathrm{CaCO}_{3}$ and spiked with $330 \mathrm{ppb} \mathrm{As}(\mathrm{III})$ and As(V)] was passed continuously through the column in one direction (from top to bottom) using a peristaltic pump at $50 \mathrm{~mL} / \mathrm{min}$ and the output water was tested for its arsenic content at 5, 50, 100 and $150 \mathrm{~L}$. The tests were discontinued as soon as the output arsenic concentration was measured beyond $10 \mathrm{ppb}$.

\section{Results}

\section{Adsorbent characterization}

XRD pattern of the adsorbent confirmed the formation of $\mathrm{CeO}_{2}$ on the surface of PAC. The $d$ values could be indexed to face-centered cubic phase of $\mathrm{CeO}_{2}$ (JCPDS card No. 34-0394). No other impurities were detected, which indicated high purity of the sample. Figure 1 shows the XRD patterns of the as synthesized adsorbent as well as

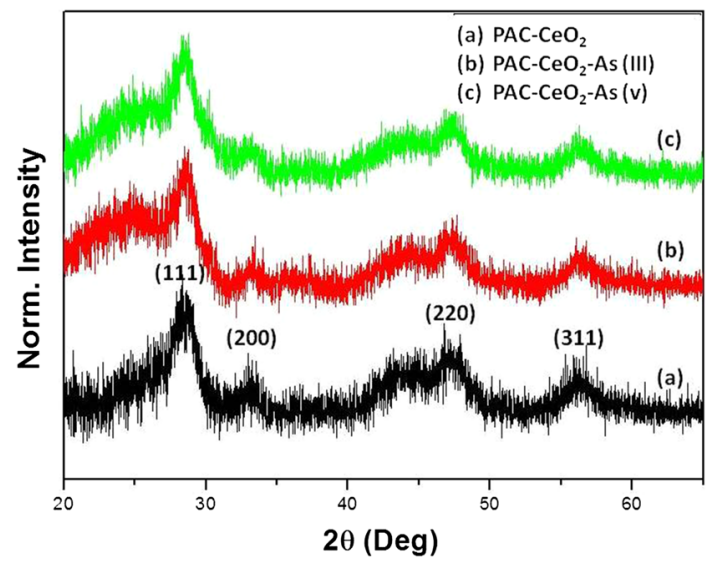

Fig. 1 XRD patterns of $\mathrm{PAC}-\mathrm{CeO}_{2}$ before and after treatment with As. The peaks are indexed to face centered cubic phase $\mathrm{CeO}_{2}$

after the Arsenic adsorption studies. No noticeable change was observed indicating the Arsenic adsorption process to be completely a surface phenomenon.

The amount of $\mathrm{CeO}_{2}$ deposited (as $\mathrm{Ce}$ ) has been quantified using ICP-OES which shows the presence of $3.5 \%$ cerium. The BET surface area of PAC decreases from initial value of $1050-635 \mathrm{~m}^{2} / \mathrm{g}$ after $\mathrm{CeO}_{2}$ deposition confirming the presence of surface deposits.

Presence of Raman shift at $461 \mathrm{~cm}^{-1}$ (Fig. 2a inset) confirmed the formation of $\mathrm{CeO}_{2}$ (Saitzek et al. 2008). The Raman shifts at $\sim 1300$ and $1589 \mathrm{~cm}^{-1}$ are due to the $G$ and $\mathrm{D}$ band of powdered activated carbon (Shimodaira and Masui 2002). Due to the strong intensity of the Raman shifts of carbon, the $\mathrm{CeO}_{2}$ peaks are shown in the inset of Fig. 2a. Figure 2a also shows the Raman shifts of the PAC- $-\mathrm{CeO}_{2}$ system after the arsenic adsorption studies. No change in the Raman shift had been observed which further confirmed the role of only surface phenomena in the adsorption process.

XPS spectra (Fig. 2b) for the adsorbent show the presence of $\mathrm{Ce}$ in it. This conforms to the Ce $3 \mathrm{~d}_{5 / 2}$ features at $882.37,887.86$, and $898 \mathrm{eV}$ and $\mathrm{Ce} 3 \mathrm{~d}_{3 / 2}$ features at $900.82,907.53$, and $916.4 \mathrm{eV}$ as reported in the literature (Cheng et al. 2008). The main peaks at 882.37 and 900.82 represent the $3 \mathrm{~d}^{10} 4 \mathrm{f}^{0}$ initial electronic state corresponding to the $\mathrm{Ce}^{4+}$ ion, while the absence of any peak at $884.9 \mathrm{eV}$ rules out the presence of any $\mathrm{Ce}^{3+}$ ions in the adsorbent.

Change of zeta potential value of PAC from -50 to $+62 \mathrm{mV}$ also confirmed the surface modification of the PAC surface.

\section{Adsorption isotherm}

The adsorption isotherm (Fig. 3a, b) was determined from equilibrium studies carried out at different As(III) and As(V) concentrations. The adsorption isotherm was plotted 

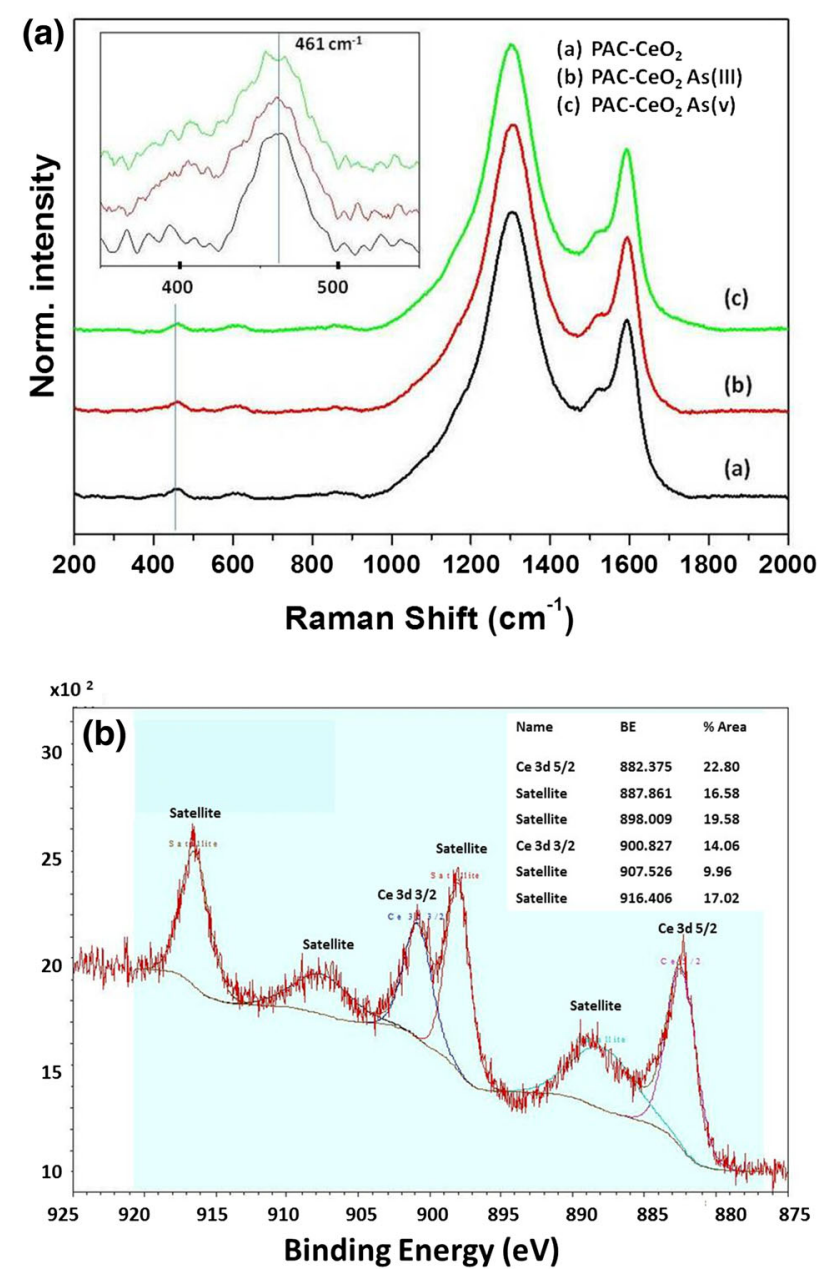

Fig. 2 a Raman shifts of PAC $-\mathrm{CeO}_{2}$ before and after treatment with $\mathrm{As}$, and $\mathbf{b}$ XPS spectrum of $\mathrm{PAC}-\mathrm{CeO}_{2}$

taking removal capacity q ( $\mathrm{mg}$ of As/g of adsorbent) on the $Y$ axis against equilibrium concentration $\mathrm{C}_{\mathrm{e}}$ (ppm) of $\mathrm{As}(\mathrm{III})$ or $\mathrm{As}(\mathrm{V})$ on the $X$ axis. The plots show best fit for
Freundlich adsorption isotherm (inset) with values $n=3.3$, $k=0.714$ and $R^{2}=0.9962$ for $\mathrm{As}(\mathrm{III})$ and $n=3.7$, $k=0.625$ and $R^{2}=0.964$ for $\mathrm{As}(\mathrm{V})$.

\section{Kinetics}

The kinetics of $\mathrm{As}(\mathrm{III})$ and $\mathrm{As}(\mathrm{V})$ removal was studied at $300 \mathrm{ppb}$ initial concentration with a adsorbent loading of $0.1 \mathrm{~g} / \mathrm{L} .80 \%$ of the adsorption was completed within first 15 min of contact for both $\mathrm{As}(\mathrm{III})$ and $\mathrm{As}(\mathrm{V})$ (Fig. 4a). This showed the effective use of $\mathrm{PAC}-\mathrm{CeO}_{2}$ adsorbent for the removal of both $\mathrm{As}(\mathrm{III})$ and $\mathrm{As}(\mathrm{V})$ without any preoxidation process. The experimental results could be best fitted with a pseudo-second-order rate kinetic model as demonstrated in Fig. $4 \mathrm{~b}$ and c. The effectiveness of the model could be justified from the $R^{2}$ values nearing 1 (Fig. 4b, c).

When the base material PAC was used as an adsorbent under the same conditions for comparison purpose, the maximum removal obtained was $10 \%$ even after $90 \mathrm{~min}$. The maximum removal capacity at equilibrium concentration of $40 \mathrm{ppm}$ was found to be $0.83 \mathrm{mg} / \mathrm{g}$.

\section{Effect of pH}

Since $\mathrm{pH}$ of water could alter the surface charge of the adsorbent/adsorbate and hence influence the kinetics and removal capacity of most of the adsorbents, Arsenic removal studies were carried out at different $\mathrm{pH}(5,6,7,8$, 9) of the input water at same arsenic concentration of 300 ppb (Fig. 5). No significant change in the removal capacity in different $\mathrm{pH}$ values in case of $\mathrm{As}(\mathrm{III})$ was observed although maximum removal was observed at $\mathrm{pH}$ 6. This could be explained on the basis of variation in arsenic species depending on $\mathrm{pH}$ values. As(III) exists predominantly as $\mathrm{H}_{3} \mathrm{AsO}_{3}$ below $\mathrm{pH} 9.2$ and as $\mathrm{H}_{2} \mathrm{AsO}_{3}{ }^{-}$
Fig. 3 Adsorption isotherm of a $\mathrm{As}(\mathrm{III})$ and $\mathbf{b} \mathrm{As}(\mathrm{V})$ on PAC$\mathrm{CeO}_{2}$. Inset show the Freundlich adsorption isotherms
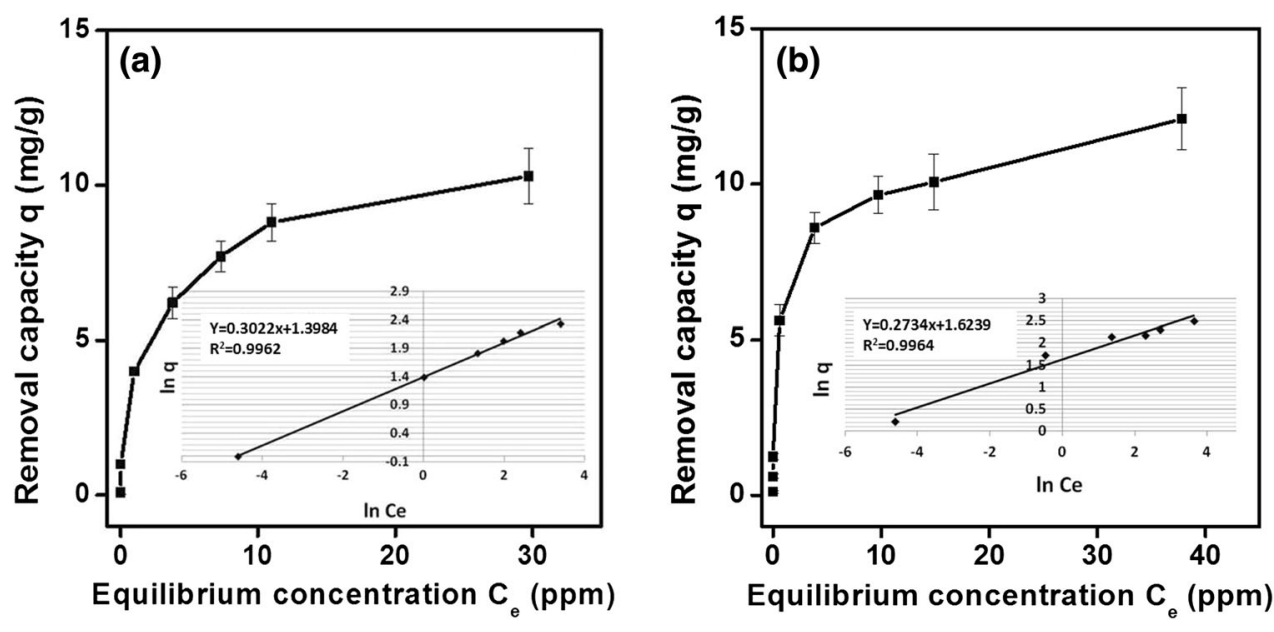
Fig. 4 a Kinetics of adsorption for $\mathrm{As}(\mathrm{III})$ and $\mathrm{As}(\mathrm{V})$ on PAC$\mathrm{CeO}_{2}$. b, c The pseudo second order rate kinetics of the adsorption process
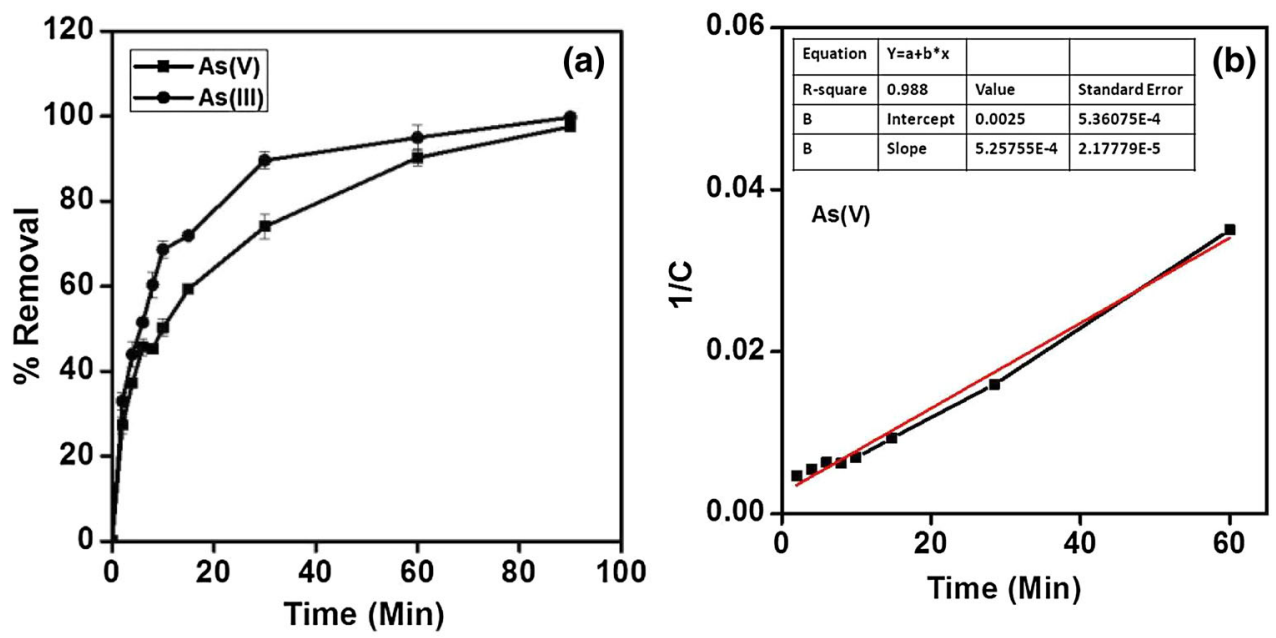

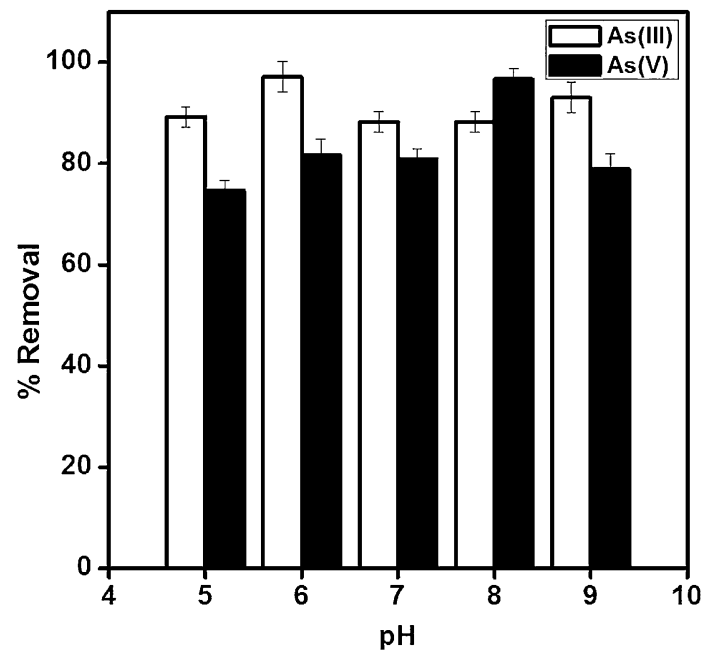

Fig. 5 Percentage removal of $\mathrm{As}(\mathrm{III})$ and $\mathrm{As}(\mathrm{V})$ by $\mathrm{PAC}-\mathrm{CeO}_{2}$ at different $\mathrm{pH}$ values

above 9.2. Since the $\mathrm{pH}$ of the experiments was below 9.2, the adsorbent did not exert any electrostatic force towards neutral $\mathrm{H}_{3} \mathrm{AsO}_{3}$ and hence no significant variation in removal. The $\mathrm{As}(\mathrm{III})$ adsorption onto $\mathrm{PAC}-\mathrm{CeO}_{2}$ was not affected by the increase of solution $\mathrm{pH}$, which suggests strong affinity existing between $\mathrm{As}(\mathrm{III})$ anions and the $\mathrm{CeO}_{2}$ particles in $\mathrm{PAC}-\mathrm{CeO}_{2}$. Thus, $\mathrm{PAC}-\mathrm{CeO}_{2}$ could be readily used for the removal of $\mathrm{As}(\mathrm{III})$ within a wide range of solution $\mathrm{pH}$, which is beneficial to their applications for water bodies with various conditions.

For As(V) the highest removal was observed at $\mathrm{pH} 8$ (Fig. 5). This observation could also be explained on the basis of $\mathrm{As}(\mathrm{V})$ speciation with respect to $\mathrm{pH}$. As(V) mainly exists in its anionic forms within the $\mathrm{pH}$ range from 4 to 10 $\left(\mathrm{H}_{2} \mathrm{AsO}_{4}{ }^{-}\right.$as the main species at $\mathrm{pH}$ range $3-6, \mathrm{HAsO}_{4}{ }^{2-}$ and $\mathrm{AsO}_{4}{ }^{3-}$ as major species at pH 8) (Deng et al. 2010). The more negative nature of the arsenic species facilitates the higher adsorption on the positively charged adsorbent at $\mathrm{pH} 8$ and hence the highest removal.

\section{Effect of counter ions}

To investigate the competing effect from co-existing anions in aqueous environment that could negatively effect the removal efficiency of the adsorbent, arsenic adsorption 


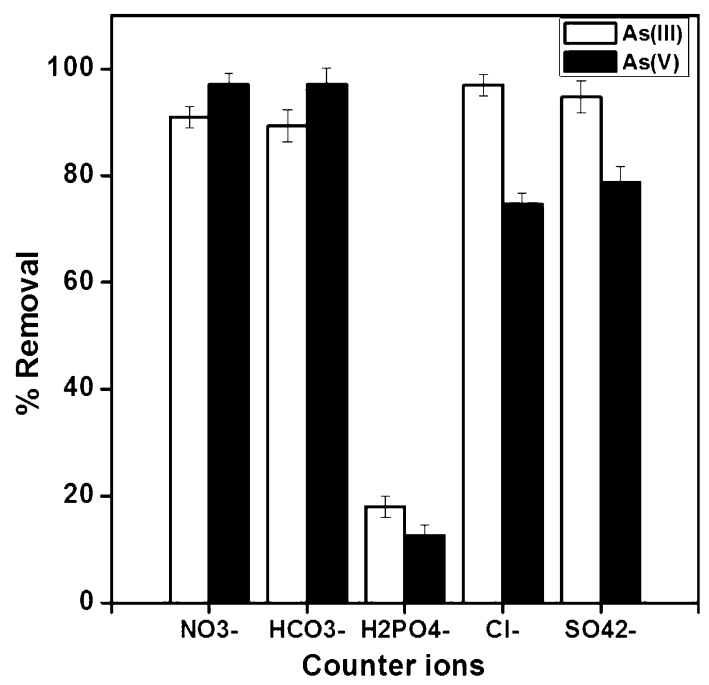

Fig. 6 Percentage removal of $\mathrm{As}(\mathrm{III})$ and $\mathrm{As}(\mathrm{V})$ by $\mathrm{PAC}-\mathrm{CeO}_{2}$ in presence of different counter ions

studies were carried out separately in presence of Sulphate, Nitrate, Chloride, Bicarbonate and Phosphate (Fig. 6). The concentration of the counter anions were maintained at $100 \mathrm{ppm}$. Even at this high concentration, presence of chloride, nitrate, sulphate and bicarbonate had negligible effect on As(III) removal. However, in the presence of $100 \mathrm{ppm}$ sodium dihydrogen phosphate, the removal drops from an average of over 90-18\%. This might be explained on the basis of their similar ionic structure that could have led to competitive adsorption ( $\mathrm{Li}$ et al. 2012). The same trend was observed in case of $\mathrm{As}(\mathrm{V})$ adsorption also. It was also observed that the percentage removal of $\mathrm{As}(\mathrm{V})$ was less compared to $\mathrm{As}(\mathrm{III})$ in presence of $\mathrm{Cl}^{-}$and $\mathrm{SO}_{4}{ }^{2-}$. This could also be explained on the basis of anionic nature of $\mathrm{As}(\mathrm{V})$ at $\mathrm{pH}$ of the experiment ( $\sim 8)$ and the competing adsorption of the ions on the adsorbent surface.

\section{Effect of humic acid}

Presence of humic acid up to 4 ppm (Fig. 7) in the test water does not have any perceivable effect on the removal As(III). The removal of As(V) was reduced slightly in the presence of humic acid. The low removal of $\mathrm{As}(\mathrm{V})$ in presence of humic acid was also observed by Rao et al. (2009) with a zero valent ion (ZVI) adsorbent.

\section{Reusability}

The reusability studies of the material using a natural hard water (TDS $1000 \mathrm{ppm}, \mathrm{pH} 7.8$, hardness $600 \mathrm{ppm}$ as $\mathrm{CaCO}_{3}$ ) spiked with $330 \mathrm{ppb}$ of $\mathrm{As}(\mathrm{III})$ or $\mathrm{As}(\mathrm{V})$ revealed that the material could be used at least three times before the output concentration of As solution exceeds the limit of $10 \mathrm{ppb}$,

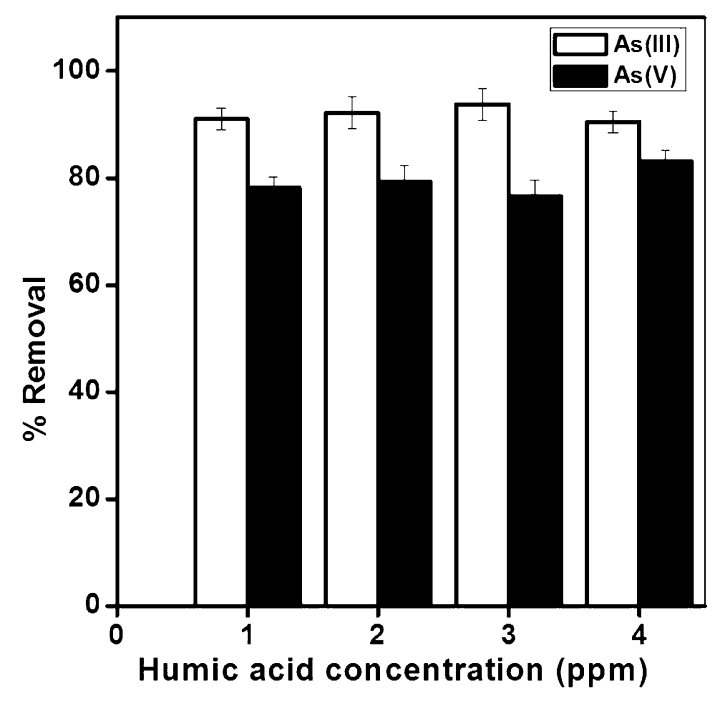

Fig. 7 Percentage removal of $\mathrm{As}(\mathrm{III})$ and $\mathrm{As}(\mathrm{V})$ by $\mathrm{PAC}-\mathrm{CeO}_{2}$ in presence of humic acid

reiterating the significance of the material as an efficient adsorbent for As removal. The material could be used even up to five times under identical conditions if the output limit is put at $50 \mathrm{ppb}$ (as per India and Bangladesh standards).

\section{Column studies}

Column studies were done with $80 \mathrm{~g}$ material in a column of $15 \mathrm{~cm}$ long acrylic column with a diameter of $3 \mathrm{~cm}$. The flow rate was maintained at $50 \mathrm{ml} / \mathrm{min}$ using a peristaltic pump. The test water was prepared using natural hard water (TDS 1000 ppm, pH 7.8, hardness $600 \mathrm{ppm}$ as $\mathrm{CaCO}_{3}$ ). Table 1 shows the values of output As concentration measured at different time points.

\section{Cerium leach}

Absence of purification byproducts or presence below maximum contamination limit (MCL) in the output water is an important factor in determining the safe usability of any adsorbent. To determine the amount of cerium leached into the output water, ICP-OES studies were done on the output water of the batch adsorption studies. With an instrument detection limit of $50 \mathrm{ppb}$, the maximum Ce concentration in the output water was found to be below detection limit at the $\mathrm{pH}$ values between 6.5 and 8.5 which accounts for most of the drinking water scenario. At acidic $\mathrm{pH}$ and $\mathrm{pH}$ values beyond 9 , we were able to detect $\mathrm{Ce}$ in the output water up to $1.1 \mathrm{ppm}$ when the equilibrium concentration of As was $10 \mathrm{ppm}$. The MCL for cerium in drinking water context is not defined in US EPA or WHO guidelines till now. Hence comments could not be made about the usability of the material at $\mathrm{pH}$ values below 6.5 or beyond 9 . 
Table 1 Output concentration of As(III) and As(V) from column studies

\begin{tabular}{lcc}
\hline Time point $(\mathrm{L})$ & As(III) $(\mathrm{ppb})$ & As(V) $(\mathrm{ppb})$ \\
\hline 5 & $<1$ & $<1$ \\
50 & 3 & $<1$ \\
100 & 9 & 7 \\
150 & 23 & 51 \\
\hline
\end{tabular}

\section{Discussion}

\section{Mechanism of removal}

The adsorption kinetics study is helpful to understand the mechanism of adsorption reactions. The pseudo-secondorder kinetic model is based on the assumption that the rate-limiting step may be chemisorption involving valency forces through sharing or exchange of electrons between sorbent and sorbate which is suitable for sorptions at low initial concentration. In this case, the pseudo-second-order kinetics indicates that the arsenic adsorption on $\mathrm{PAC}-\mathrm{CeO}_{2}$ happens through chemisorption, which has also been discussed in the FTIR study ( $\mathrm{Li}$ et al. 2012; Cui et al. 2012). This result was also supported by the X-ray diffraction and Raman studies that indicated no change into the crystal structure or surface properties of the adsorbent before and after the arsenic adsorption studies.
The mechanism of arsenic removal was further investigated using FTIR technique. To ensure quantitative analysis, samples were mixed at $1 \%$ with $\mathrm{KBr}$ by weight. From the spectra it could be seen that before the arsenic adsorption (Fig. 8a), strong $\mathrm{OH}$ stretching and bending vibrations of surface adsorbed water at 3435 and $1629 \mathrm{~cm}^{-1}$ along with $\mathrm{Ce}-\mathrm{OH}$ bending vibrations at $1110,1055,930 \mathrm{~cm}^{-1}$, are present. After the arsenic adsorption experiments (Fig. 8b, c), the $\mathrm{Ce}-\mathrm{OH}$ bending vibrations disappeared and a new vibration at $839 \mathrm{~cm}^{-1}$ appeared which could be attributed to $v$ (As-OCe) bond. Appearance of this vibration at $815 \mathrm{~cm}^{-1}$ for adsorption of arsenic onto $\mathrm{TiO}_{2}$ was reported by Pena et al. (2006). Li et al. (2012) reported observation of the same peak at $805 \mathrm{~cm}^{-1}$. Appearance of this As-O-Ce vibration indicates that the adsorption of both As(III) and As(V) follows the inner sphere mechanism. The FTIR studies indicate that the substitution of $\mathrm{OH}$ groups by As from $\mathrm{Ce}-\mathrm{OH}$ plays a major role in the adsorption process which could also be explained through specific adsorption mechanism. The specific adsorption involves ligand exchange reactions where the anions displace $\mathrm{OH}^{-}$and/or $\mathrm{H}_{2} \mathrm{O}$ from the surface (Hingston et al. 1967).

Since the surface charge of the $\mathrm{PAC}-\mathrm{CeO}_{2}$ adsorbent was positive in the experimental $\mathrm{pH}$ range, the coulombic attraction between the positive surface and negative anions also played a role in giving the adsorbent a high removal capacity for both $\mathrm{As}(\mathrm{III})$ and $\mathrm{As}(\mathrm{V})$ across $\mathrm{pH}$ ranges.

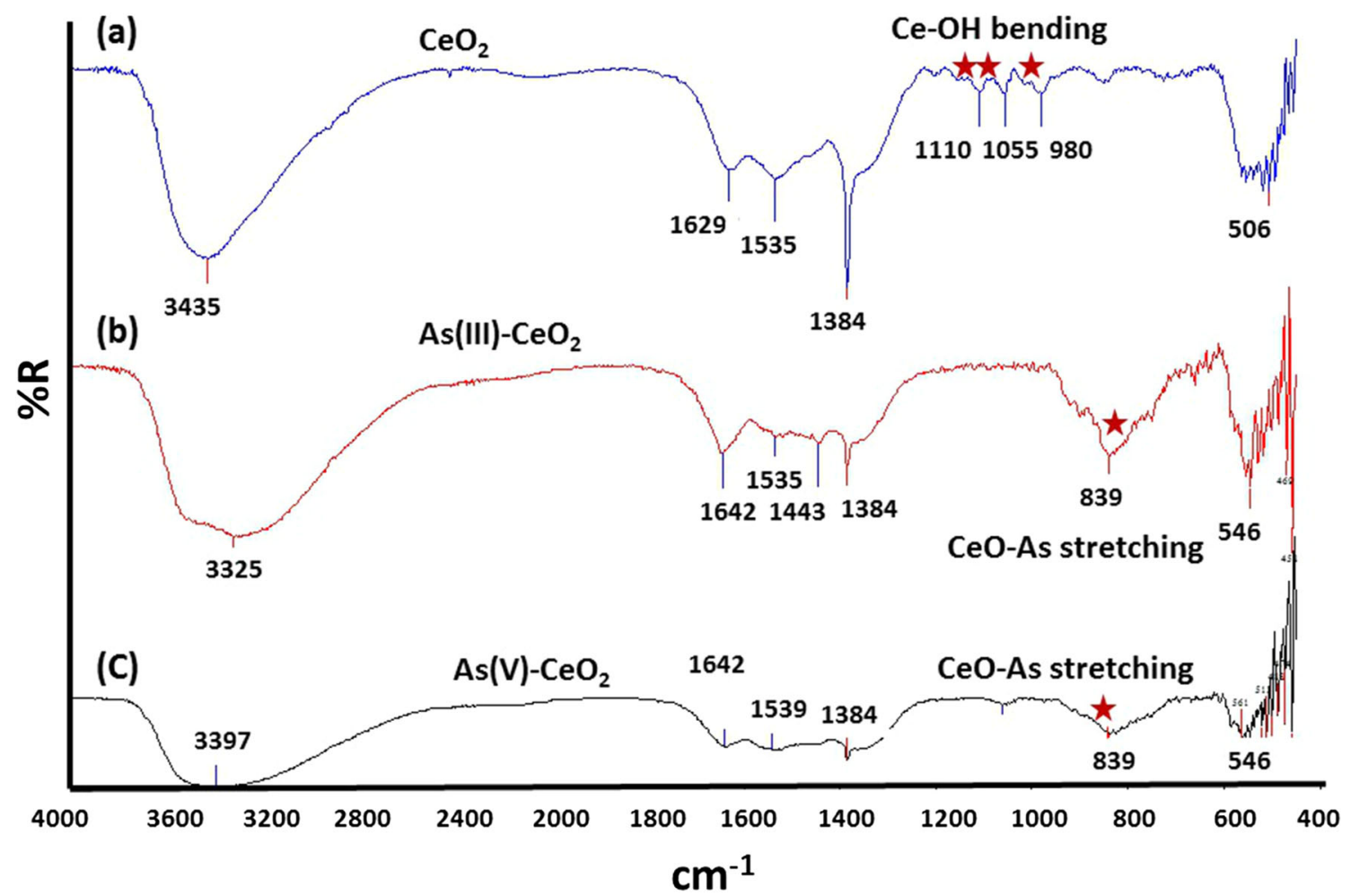

Fig. 8 FTIR spectra of PAC- $\mathrm{CeO}_{2}$ a before and $\mathbf{b}$ after removal of As(III) and $\mathbf{c}$ after removal of $\mathrm{As}(\mathrm{V})$ 


\section{Conclusion}

The $\mathrm{CeO}_{2}$ coated powdered activated carbon $\left(\mathrm{PAC}-\mathrm{CeO}_{2}\right)$ is highly efficient as an adsorbent for arsenic removal from drinking water. The maximum removal capacity was found to be nearly $12 \mathrm{mg} / \mathrm{g}$ for both $\mathrm{As}(\mathrm{III})$ and $\mathrm{As}(\mathrm{V})$. The efficiency of removal was not affected by change in $\mathrm{pH}$, salinity, hardness, organic and inorganic anions excluding phosphate. The mechanism of removal is through both specific adsorption and columbic attraction. With no pretreatment required, the adsorbent could be highly competitive for POU devices in terms of cost, ease of use and removal efficiency.

Acknowledgments Authors are thankful to Dr. Neha Hebalkar from ARCI, Hyderabad, India, for her help in recording the XPS.

Open Access This article is distributed under the terms of the Creative Commons Attribution 4.0 International License (http:// creativecommons.org/licenses/by/4.0/), which permits unrestricted use, distribution, and reproduction in any medium, provided you give appropriate credit to the original author(s) and the source, provide a link to the Creative Commons license, and indicate if changes were made.

\section{References}

Ahmad SA, Bandaranayake D, Khan AW, Hadi SA, Uddin G, Halim A (1997) Arsenic contamination in ground water and arsenicosis in Bangladesh. Int J Environ Health Res 7:271-276

Ali I (2010) The quest for active carbon adsorbent substitutes: inexpensive adsorbents for toxic metal ions removal from wastewater. Sepn Purfn Rev 39:95-171

Ali I (2012) New generation adsorbents for water treatment. Chem. Revs. 112:5073-5091

Ali I, Asim M, Khan TA (2012) Low cost adsorbents for removal of organic pollutants from wastewater. J Environ Manag 113:170-183

Ali I, Al-Othman ZA, Alwarthan A, Asim M, Khan TA (2014) Removal of arsenic species from water by batch and column operations on bagasse fly ash. Environ Sci Pollut Res Int 21(5):3218-3229. doi:10.1007/s11356-013-2235-3

Argos M, Kalra T, Rathouz PJ, Chen Y, Pierce B, Parvez F, Islam T, Ahmed A, Zaman RM, Hasan R, Sarwar G, Slavkovich V, Alexander G, Graziano J, Ahsan H (2010) Arsenic exposure from drinking water, and all-cause and chronic-disease mortalities in Bangladesh: a prospective cohort study. Lancet 376:252-258

Bordoloi S, Nath SK, Gogoi S, Dutta RK (2013) Arsenic and iron removal from groundwater by oxidation-coagulation at optimized pH: laboratory and field studies. J Hazard Mater 260:618-626

Chen SL, Dzeng SR, Yang MH (1994) Arsenic species in ground waters of the blackfoot disease area, Taiwan. Environ Sci Technol 28:877-881
Cheng DG, Chong M, Chen F, Zhan X (2008) XPS characterization of $\mathrm{CeO}_{2}$ catalyst for hydrogenation of benzoic acid to benzaldehyde. Catal Lett 120:82-85

Chowdhury TR, Basu GK, Mandal BK, Biswas BK, Samanta G, Chowdhury UK, Chanda CR, Lodh D, Roy SL, Saha KC, Roy S, Kabir S, Quamruzzaman Q, Chakraborti D (1999) Arsenic poisoning in the Ganges delta. Nature 401:545

Cui H, Li Q, Gao S, Shang JK (2012) Strong adsorption of arsenic species by amorphous zirconium oxide nanoparticles. J Ind Eng Chem 18:1418-1427

Hingston FJ, Atkinson RJ, Posner AM (1967) Specific adsorption of anions. Nature 215:1459-1461

Karim M (2000) Arsenic in groundwater and health problems in Bangladesh. Water Res 34:304-310

Li Z, Deng S, Yu G, Huang J, Lim VC (2010) As(V) and As(III) removal from water by a $\mathrm{Ce}-\mathrm{Ti}$ oxide adsorbent: behavior and mechanism. Chem Eng J 161:106-113

Li R, Li Q, Gao S, Shang JK (2012) Exceptional arsenic adsorption performance of hydrous cerium oxide nanoparticles: part A. Adsorption capacity and mechanism. Chem Eng J 185-186:127-135

Maji SK, Pal A, Pal T (2008) Arsenic removal from real-life groundwater by adsorption on laterite soil. J Hazard Mater 151:811-820

Mohan D, Pittman CU Jr (2007) Arsenic removal from water/ wastewater using adsorbents-a critical review. J Hazard Mater 142:1-53

Nguyen CM, Bang S, Cho J, Kim KW (2009) Performance and mechanism of arsenic removal from water by a nanofiltration membrane. Desalination 245:82-94

Pena M, Meng XG, Korfiatis GP, Jing CY (2006) Adsorption mechanism of arsenic on nanocrystalline titanium dioxide. Environ Sci Technol 40:1257-1260

Rao P, Mak MSH, Liu T, Lai KCK, Lo IMC (2009) Effects of humic acid on arsenic(V) removal by zero-valent iron from groundwater with special references to corrosion products analyses. Chemosphere 75:156-162

Sabbatini P, Yrazu F, Rossi F, Thern G, Marajofsky A, Fidalgo de Cortalezzi MM (2010) Fabrication and characterization of iron oxide ceramic membranes for arsenic removal. Water Res 44:5702-5712

Saitzek S, Blach JF, Villain S, Gavarri JR (2008) Nanostructured ceria: a comparative study from X-ray diffraction, Raman spectroscopy and BET specific surface measurements. Physica status solidi (a) 205:1534-1539

Shimodaira N, Masui A (2002) Raman spectroscopic investigations of activated carbon materials. J Appl Phys 92:902-909

Wickramasinghe SR, Han B, Zimbron J, Shen Z, Karim MN (2004) Arsenic removal by coagulation and filtration: comparison of groundwaters from the United States and Bangladesh. Desalination 169:231-244

Xu W, Wang J, Wang L, Sheng G, Liu J, Yu H, Huang XJ (2013) Enhanced arsenic removal from water by hierarchically porous $\mathrm{CeO}_{2}-\mathrm{ZrO}_{2}$ nanospheres: role of surface- and structure-dependent properties. J Hazard Mater 260:498-507

Zhang Y, Yang M, Huang X (2003) Arsenic(V) removal with a Ce(IV)-doped iron oxide adsorbent. Chemosphere 51:945-952

Zhang S, Niu H, Cai Y, Zhao X, Shi Y (2010) Arsenite and arsenate adsorption on co-precipitated bimetal oxide magnetic nanomaterials: $\mathrm{MnFe}_{2} \mathrm{O} 4$ and $\mathrm{CoFe}_{2} \mathrm{O} 4$. Chem Eng J 158:599-607 